\title{
Virtual Communities of Learning: New Challenges in Teaching Learning Process in Higher Education
}

\author{
Byron Hidalgo ${ }^{1,2^{*}}$, Luis Rivera ${ }^{3}$ and Rosa Delgadillo \\ 'Major National, University of San Marcos, Peru; byron.hidalgo@unmsm.edu.pe, rdelgadilloa@unmsm.edu.pe \\ ${ }^{2}$ National University of Chimborazo, Ecuador \\ ${ }^{3}$ State University of Norte Fluminense, Brazil; rivera@uenf.br
}

\begin{abstract}
Objectives: Advantages of Information and Communication Technologies (ICT) in the educational process objectify us to explore the advances of Learning Management Systems (LMS), and preferences of Social Network Sites (SNS), as effective and attractive platforms in university education. Method/Analysis: Pursuing the objective, a set of articles related to the topic are analyzed qualitatively, according to the characteristics of the LMS tools in the improvement of the interaction in the educational process, as well as the characteristics of the SNS for virtual learning communities, and the dimensions that the interaction of these two tools must acquire, for an effective teaching-learning process. Findings: The work shows the trends of use of SNS, in particular Facebook, in informal learning that can be used efficiently in formal learning by attaching to LES platforms, in particular Moodle, with pedagogical, motivational and construction rules Social. Diverse discussions in the literature show that the LMS are not fulfilling the objectives proposed because they lack a social presence, an effective motivation to use, and because they tend to be tendencies to be technical repositories. Applications/Improvements: As a consequence, we suggest models of educational focus based on the synergies of LMS tools and social networks with technological, pedagogical, cognitive and social approaches for face-to-face and virtual education.
\end{abstract}

Keywords: bLearning, eLearning, LMS-SNS, Social Presence in Learning, Teaching-Learning Technology, Virtual Learning Community

\section{Introduction}

With the constant development of ICT, and especially with the advantages that the Internet offers for the functionality of various platforms and social services, a new paradigm emerges in the field of education. This new model of interaction between educational actors, gives birth to a new form of communication, collaboration and cooperation, which emphasizes the dynamic educational process.

We are at a time when ICT has a presence almost in all human activity, and could not go unnoticed in the educational field, so many people are very engaged in their training community in person, but on the other hand In part, different studies show that the virtual community also reaches levels of commitment equal to or higher than face-to-face. This leads us to consider that mixed learn- ing (bLearning) emerges from the synergy of these two modalities.

Vygostsky' $s^{1}$ socio-cultural theory of learning affirms “... people learn through social interaction and the exchange of ideas and experiences". According to previous studies of Vygostsky'swork on social construction as a learning mechanism, it is affirmed that social processes promote cognitive change through the process of interaction.

Therefore, the exchange of knowledge has a significant influence on the conversion of social knowledge into individual knowledge, and vice versa. The present study is born from the evolutionary idea, when trying to know if the interaction of the users in the SNS environments lead and provoke an interactive, communicative and collaborative behavior ${ }^{2}$, being these the main characteristics of the social presence, and that these factors can influence

*Author for correspondence 
significantly in the educational process in synergy with the LMS, combining informal and formal training.

In the years, universities have tried to incorporate in their environment, learning environments and eLearning as bLearning adopting the LMS in its educational process, which combine characteristics of technological and instructional type ${ }^{3}$; however, it is necessary to analyze how the SNS that have been achieved by a great popularity and attraction of the studies, these particular characteristics can be considered in synergy. To achieve a modern, customizable and evolutionary environment, encouraging learning communities with social and interactive presence, either in the eLearning and/or bLearning environment.

In this work, the study is based on the review of the literature regarding the use of technological tools in the educational process, both formal and informal, for which the following objective of research is presented: knowing whether the synergy of these two technology SNS and LMS tools will achieve the active and participatory participation with students with a cognitive social presence promoting the interaction, communication and collaboration among the educational actors, to break the closed walls of the traditional LMS, interrupting the formal imbalances of power between the student, teacher and the university.

To achieve the objective, some questions are set:

Which characteristics should the LMS tools have to improve the interaction in the educative process?

Which characteristics the SNS have to contribute to establish Virtual Communities of Learning (VCL)?

What dimensions should the SNS and the LMS reach a new educational environment that involves to significantly promote the teaching- learning process?

\section{Methodology}

A systematic review of the literature was performed following the main coordinates established by Garcia ${ }^{4}$ and Schryen ${ }^{5}$, that is, the establishment of the approach (subject, domain, discipline), result (the synthesis and interpretation of the literature and guidance for future research), the framework (the systematization of a conceptual review) and the development of phases (the search and evaluation, synthesis and interpretation, conclusions).

In terms of the approach, the issue of the review of the literature are "the SNS in the educational field" and "LMS in higher education". The work is intended to respond to the creation of new knowledge, starting and resuming the analysis of inner sector lines, sorting and meaningless to the variable conceptual parts within an integrating framework, designing a series of macro consistent concepts, being the fundamental point. The discovery of gaps in knowledge that are important for the explorations of research with a construction approach to theories, challenging the horizon of current knowledge in the field and giving a new reference framework. By adding to the acquisition of knowledge in the crossroads of different fields, the end of the review of the literature is: to determine the dimensions of each of these tools recognizing their strengths and decreasing their weaknesses so that in the synergy of the enhanced educational environment can be achieved, where students can obtain active and collaborative participation with a cognitive social presence promoting the interaction, communication and collaboration among the education of the university.

The study examines the scope of the bibliographic review as follows: First the relevance of the SNS was analyzed in the educational field and the LMS in higher education; seconds were certain limits: the revision of the literature should be based on interdisciplinary studies arising from concurrent perspectives such as: communication, cooperation, collaboration, social interaction, formal education, informal education, casual, moodle, focusing on the articles published in the best-classified magazines and indexed in Web of Science ${ }^{4}$ : considering mainly studies on the importance of the SNS (Facebook) in the educational context and the LMS (Moodle) in the education higher logical search chain applied to titles and summaries, by introducing keywords and phrases in the couplist of a magazine selected, respectively ${ }^{6}$, "The Usage of Social Networking Sites for Education", "Learning Management Systems for Higher education".

With course the systematic search of the literature a relevant amount of information was found. The classification and filtrate was made to obtain a relatively large number of current and relevant contributions, the identification of some books and documents presented in renovated international conferences. The search was considered when the new articles found only had presented arguments and points of view (Figure 1).

In order to ensure consistency in the evaluation phase of the literature, the analysis was carried out after defining the specific selection criteria that include both the quality and the fit of the article. The formal requirements of quality contemplated refer to the availability of extensive 
reviews of the literature that cover constructions based on similarities (communication, cooperation, collaboration, social interaction, formal education, informal education, Facebook, Moodle) in the context of SNS and LMS. In the interpretation phase, the aim is to advance and adopt a new perspective centered on the concept of the integration of these two tools in the university educational environment.

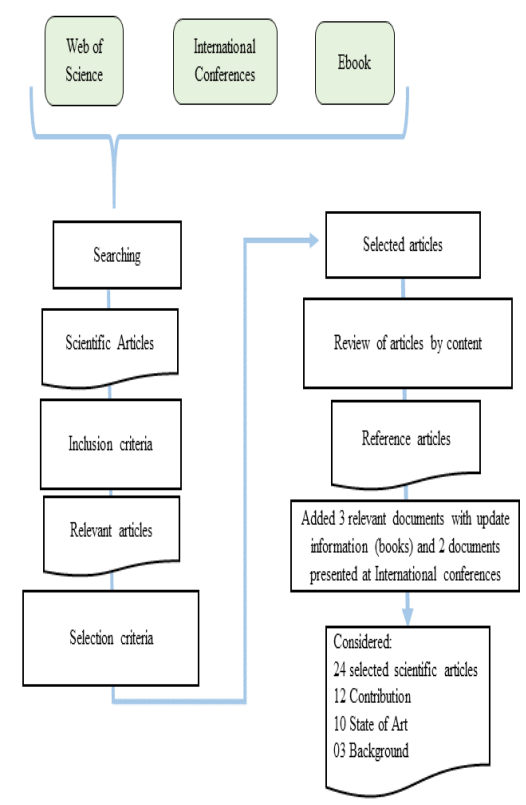

Figure 1. Search criteria, inclusion and selection of literature.

After a classification and interpretation of the heterogeneous theoretical concepts, in broader conceptual categories, significant approaches emerged on attributes and components of similarity between the SNS and the LMS.

From these similarities were located the structures of: application in education, values, interests, preferences, hobbies, entertainment, social influence, and social interaction. These dimensions are indicative of the intricate processes of social interaction that support and consolidate the development of SNS in the educational field, and in particular of Facebook.

\section{Virtual Communities of Learning (VCL)}

The virtual communities of learning take place thanks to the great advantages that the Internet and ICT offer us, promoting possibilities of socialization and interaction, giving rise to the fact that cyberspace becomes the space of the VCL; a space that is not geographical, but electronic

VCL appears when a group of students use ICT to communicate and interact with each other through telematic networks that provide a structure, activities, resources, methodology and teaching-learning processes that promote discussions and comments on specific topics of interest that are linked to the accomplishment of tasks, research or pursuing common interests making their users develop mutual feelings of belonging and cohesion.

With the emergence of ICT, we moved from the faceto-face classroom environment to a virtual one, where autonomous learning took place, the performance of teamwork and other possibilities that these settings allow. Because of the development of these surroundings, both students and teachers must adopt new technological competencies that foster environments in which interaction, social presence and the use of electronic resources evolve, promoting a comfortable environment for the educational setting.

In this context, CVA should be a community that encourages, the communication, cooperation and sharing resources and activities within a whole social environment. A social presence can get the adhesion of the students getting an open platform, holistic according to current needs, breaking the formalism of higher education.

\subsection{Moodle as a Learning Community}

ICT can facilitate universal access to education, reduce differences in learning, support the development of teachers in improving the quality and relevance of the teaching-learning process, strengthen the incorporation and development of the management and administration of education ${ }^{7}$, so the incidence of the use of technological tools in university education, whether formal or informal, is essential, forming autonomous and critical students? ${ }^{7}$.

LMS also referred to as Resource Management System (RMS) or Virtual Learning Environments (VLE) are web-based applications, in which students can access content in different formats (text, image, sound, video) to interact with Teachers and colleagues through text messages, forums, chats, video conferences or other types of communication tools ${ }^{8}$. These platforms provide a set of configurable features, which allow the creation of online courses, which follows an instructional design maintaining a methodological structure. Teachers have content 
management tools to record, monitor and evaluate student activities.

LMS serve as support in the teaching- learning process as a virtual tool in the universities. They are web applications, executed on a server and accessible through a web browser, from anywhere with Internet connection? The use of LMS is a current reality in higher education institutions, the main role of which is to provide support for bLearning programs and to support pedagogical and didactic activities in classroom teaching ${ }^{10}$.

In Table 1 the LMS is summarized according to access criteria, divided into two groups: commercial or owner, and open or free-source-code (developed by educational institutions, generally). Currently nobody questions the validity of the Open Source model as a stable solution, and with high credibility as Moodle, which has been consolidated as the leader of the Open Source model, however, the owner model headed by Blackboard has also managed to dominate the proprietary appliance space.

Table 1. Types of LMS

\begin{tabular}{|l|l|}
\hline CommercialorOwner & Open Source \\
\hline Blackboard & Dokeos \\
eCollege & Claroline \\
Fronter & dotLRN \\
SidWeb & Moodle \\
e-ducativa & Sakai \\
QSmedia & \\
Saba & \\
\hline
\end{tabular}

The particularities of all LMS must be to maintain effective communication between human users and systems; flexibility to accompany their academic process traveling for students; to support a varied number of users interacting at the same time; presence of criteria of common characteristics of use; intuitive access to the platform where inspire the user continue to use, user satisfaction in acquisition knowledge; a system that can be accessible for any user and be used in any necessary infrastructure; ability to attract and loyalty a to a user. In summary, LMS must have attributes ${ }^{11}$ such as interactivity, flexibility, scalability, standardization, usability, functionality, ubiquity, accessibility and persuadability.

LMS software with those attributes, in particular, free software, acquires excellent impact. In the educational field and, according to the world ranking of universities on the web ${ }^{12}$, trends are identified in terms of the type of LMS used in university education, is the most accepted
Moodle followed by Blackboard and finally by Frontier $\frac{13}{}$. Table 2 illustrates the preference of LMS uses in the best universities of the United States, Europe, and Latin America.

Figure 2 illustrates the comprehensive work of the most used LMS in all administrative, business, education, among others, the observation of the Moodle and Blackboard platforms is observed.

However, the preference by the Moodle platform that is evident would be associated with technical aspects such as possessing, in a way, the attributes desired by LMS, with high capacity of extension and being open source. Moodle is a flexible tool that promotes the collaborative tool that supports the work. Collaborative and training that awakens the interest of students towards technologies and that align with the benefits of a digital native ${ }^{15}$. The characteristics that possess the LMS, as a pedagogical tool, with a student interface and teaching, means of administration, security, support, accessibility, security, support, and the accessibility of formal education platform.

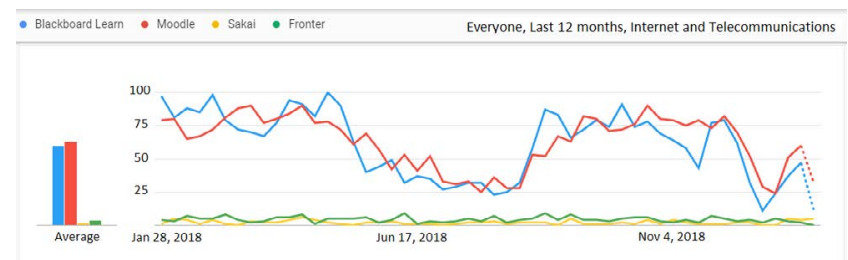

Figure 2. Statistics of use of Platforms LMS13.

\subsection{Facebook as a Learning Community}

The use of ICT, in particular, social networks, as means of interaction promote communication, discussion by offering a wide range of advantages for the knowledge exchange process such as social labeling that allows emotional partner expressions in conversations, creating visual content, audio along with the text by offering opportunities to communicate synchronously ${ }^{16}$. Currently, there is a variety of SNS available, with the most used, and even in academic books. He was born in the academy and has become the most popular among the university students who have already made and an essential part of their social life ${ }^{10}$.

Facebook is eminently known as a social media activity center; however, it is being recognized quickly as electronic learning, remembered and successful learning $\frac{17,18}{}$. SNS Facebook has been successfully implemented as an online learning environment in higher education around 
Table 2. Trends of LMS used in University Education ${ }^{14}$

\begin{tabular}{|c|c|c|c|c|c|c|}
\hline & \multirow[t]{2}{*}{ Ranking } & \multirow[t]{2}{*}{ Universidad } & \multicolumn{4}{|c|}{ LMS } \\
\hline & & & Moodle & Blackboard & Sakai & Fronter \\
\hline \multirow{10}{*}{$\begin{array}{l}\text { ESTADOS } \\
\text { UNIDOS }\end{array}$} & 1 & Harvard University & & $\mathrm{X}$ & & \\
\hline & 2 & Stanford University & $\mathrm{X}$ & $\mathrm{X}$ & $\mathrm{X}$ & \\
\hline & 3 & Massachusetts Institute of Technology & & & $\mathrm{X}$ & \\
\hline & 4 & CornellUniversity & $\mathrm{X}$ & $\mathrm{X}$ & & \\
\hline & 5 & University of California Berkeley & & & $\mathrm{X}$ & \\
\hline & 6 & University of Michigan & & & $\mathrm{X}$ & \\
\hline & 7 & University of Wisconsin Madison & $\mathrm{X}$ & & & \\
\hline & 8 & University of Washington & $\mathrm{X}$ & $\mathrm{X}$ & & \\
\hline & 9 & University of Minnesota & $\mathrm{X}$ & & & \\
\hline & 10 & University of Pennsylvania & & $\mathrm{X}$ & $\mathrm{X}$ & \\
\hline \multirow[t]{10}{*}{ EUROPA } & 1 & University of Cambridge University & & & $\mathrm{X}$ & \\
\hline & 2 & University of Oxford & & & $\mathrm{X}$ & \\
\hline & 3 & University of Ssouthampton & & $\mathrm{X}$ & & \\
\hline & 4 & UniversityCollege London & $\mathrm{X}$ & & & \\
\hline & 5 & Swiss Federal Institute of Technology & $\mathrm{X}$ & & & \\
\hline & 6 & University of Oslo & & & & $\mathrm{X}$ \\
\hline & 7 & University of Edinburgh & $\mathrm{X}$ & $\mathrm{X}$ & & \\
\hline & 8 & Utrecht University & & $\mathrm{X}$ & & \\
\hline & 9 & University of Helsinski & $\mathrm{X}$ & & & \\
\hline & 10 & UniversitätWien & $\mathrm{X}$ & & & $\mathrm{X}$ \\
\hline \multirow{10}{*}{$\begin{array}{l}\text { AMERICA } \\
\text { LATINA }\end{array}$} & 1 & Universidade de São Paulo & $\mathrm{X}$ & & & \\
\hline & 2 & $\begin{array}{l}\text { Universidad Nacional Autónoma de } \\
\text { México }\end{array}$ & $\mathrm{X}$ & & & \\
\hline & 3 & $\begin{array}{l}\text { Universidade Federal do Rio Grande do } \\
\text { Sul }\end{array}$ & $\mathrm{X}$ & & & \\
\hline & 4 & Universidade Estadual de Campinas & $\mathrm{X}$ & & $\mathrm{X}$ & \\
\hline & 5 & Universidade Federal do Rio de Janeiro & $\mathrm{X}$ & & & \\
\hline & 6 & Universidade Federal de Santa Catarina & $\mathrm{X}$ & $\mathrm{X}$ & & \\
\hline & 7 & Universidad de Chile & $\mathrm{X}$ & & & \\
\hline & 8 & $\begin{array}{l}\text { Universidade Estadual Paulista Júlio de } \\
\text { MesquitaFilho }\end{array}$ & $\mathrm{X}$ & & & \\
\hline & 9 & Universidade Federal de Minas Gerais & $\mathrm{X}$ & & & \\
\hline & 10 & Universidad de Buenos Aires & $\mathrm{X}$ & & & \\
\hline
\end{tabular}

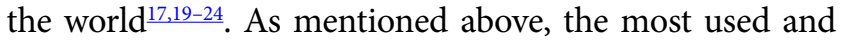
popular SNS is Facebook with 2,196 billion monthly active users $^{25}$, is illustrated in Figure 3, followed by YouTube.

One of the main factors of social networks is the communicative potential ${ }^{26}$, as well as the social factor that is a subject that draws attention ${ }^{27}$. Besides, the Facebook environment provides a variety of options for interac- tion, collaboration, and exchange of knowledge $e^{\underline{23}}$. Social networks have played an important role in collaborative work, highlighting three fundamental aspects that must be emphasized from the social network when working cooperatively: the degree of commitment of students in the system, social interaction, and the possibility of creating closed workgroups. 


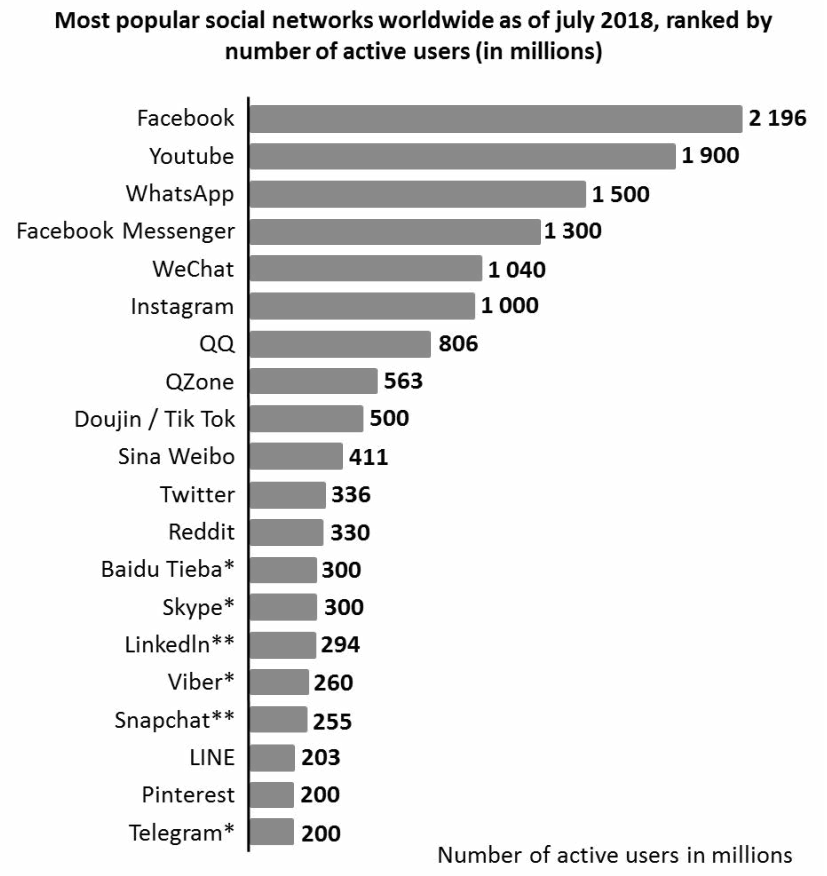

Figure 3. Social Networks Site ${ }^{25}$.

\section{Discussions}

Currently, research is beginning to focus on the relationship between LMS and SNS, with the aim of improving organizational learning of E-Learning with social learning 1 . Many higher education institutions recognize the need for specific online learning guidelines and are taking an initiative to devise effective policies. The University of Glasgow, for example, published "eLearning Strategy 2013-2020", a technical document that describes the best practices for the teaching-learning process in the university, which increases the reach and accessibility of online learning methods that the faculty can adopt. Among its priorities is the use of a flexible virtual environment that incorporates interactive features to make learning more social for students ${ }^{28}$. In this current Johnson and colleagues ${ }^{29}$ say that “... social networks are vehicles to deepen learning ..."

In Yilmaz's ${ }^{30}$ work VCL is created on Facebook, in which students share their knowledge and experiences on the issues that are taught during the initial computer course. The method promotes the discussion, providing tracks, resources, materials on the subject, which has not been able to understand or on the assigned task by the B-Learning mode. In that expertise, students exhibited the behavior of knowledge exchange (KSB) on the topics of the course, as also of topics of other courses throughout the semester. Finally, it was determined and state of the social presence factors (trans) and the Transactional (T), which is the interaction with the proportion of the environment through a proposed model of the equations, showing that the KSB of the students are related to their perceptions of SP and TD in the way of using virtual learning communities, as they also indicate that each subdimension of these factors are correctly predictable in KBS.

In works about education models using Facebook show that interactions in the face-based virtual learning community are very relevant, and they claim that students increased acceptance and use of technology as a result of most students who experienced using this social network ${ }^{27}$. The social status presents is directly related to the cognitive presence, thus improving the interactions and creation of reflective discussions $s^{31,32}$. This stream has adhered the authors Ma and $\mathrm{Chan}^{1}$ to the segment: "The motivation of perceived online relationships has a direct and significant effect of the online knowledge exchange and the perceived commitment of the perceived online relationship has a direct and significant effect on online knowledge sharing behavior ...."

Last ten years, the reasons for an exponential growth number of people who use Facebook have been identified, two main factors that undergo their use, such as external stimulation that encourages users to participate in behaviors that deal with Facebook (for example; birthday reminders, automatic emails sent by the social network), and the internal motivations that deal with the gratifications provided by the content and use of the media ${ }^{33}$. That is, the social connection, join groups and organize events, publish and view photographs, among others ${ }^{34}$. In the relevant literature they state that by engaging in social interaction through SNS, there is the potential to increase subjective well-being ${ }^{34}$, the compatibility between technology and users, and the attitude towards technology ${ }^{35}$. Moretta and Buodo ${ }^{36}$ affirms that young Italian adults use Facebook to regulate mood, which in itself has more impact than social interaction online, which contrasts with the work of Caplan ${ }^{37}$ that there is growing evidence that employers use of SNS is social interaction, considered as a key cognitive component of Internet use that predicts how people use this resource. The problem of internet use represents a phenomenon worthy of academic attention. There are negative and positive considerations in this regard. The negative aspects $\frac{38,39}{}$ are that Facebook could be a context where the user is more likely to engage in addic- 
tive behaviors that lead to problematic consequences. Facebook offers different features that can make its use addictive, as well as the exposure of intimate or personal information ${ }^{49}$. Positive facts are based on positive results in the context of education $\frac{35}{}$. Mainly, students' purposes for the use of SNS in higher education are easy and convenient ways to search information, effective ways to contact or communicate with their classmates and speakers, as well as maintain a closer relationship among their friends. All this is opposed by Chinese authors ${ }^{40}$ who say that with the development of social networks users have accepted this interactive method hidden, that they even enjoy this process. But without a doubt, most of the users' time on social networks is for entertainment.

It is clear that social networks promote communication, social interaction that causes a direct relationship with cognitive presence, interactive use, information, and search, external and internal stimulation which implies the adhesion of the users, the exchange of knowledge, the creation of groups, and the perceived commitment. All these factors indicate that social networks have potential in the educational field. Everybody knows that social networks were created for entertainment initially- such as making friends online, communicating informally with a high social presence, commenting on its walls, among others- however, these related and regulated factors will give positive results in the Teaching- Learning process.

The LMS are considered as pedagogical platforms, as well as Moodle that has social constructivism as a pedagogical principle. They are robust platforms in options, tools, and other formats, which, without teacher mediation and interaction with the student's effort to carry out the proposed activities, learning will hardly happen. Various projects have compared the positive impact on the academic results of students who use teaching methodologies that incorporate the use of LMS. In the study conducted by Gunes and Altintas ${ }^{41}$, at the University of Istanbul Aydin (Turkey), they compare the practical impact of distance education using LMS. However, the benefits derived from the use of online teaching methodologies are not only reflected in the purely academic results but also have an impact on the professional development of the students.

The results of the investigations carried out are compatible with the reports of teaching institutions. For example, with the ECAR Study of Undergraduate Students and Information Technology report ${ }^{42}$, conducted among more than 113,000 students from 14 countries, they value positively how these technologies help them achieve their academic goals and prepare them for their future educational and labor activities. According to this report, approximately three out of four students agree that the technology helped them in academic goals $(76 \%$ in the USA, $75 \%$ in Canada and $72 \%$ in the rest of the countries), and more or less the same proportion agrees that technology prepares them better for future courses. The majority of students, approximately three out of five, also agree that the technology used in their training process better prepares them for their future work $(61 \%$ in the USA, $58 \%$ in Canada, and $56 \%$ in the other countries) and these results are consistent regardless of regional and demographic differences.

Moodle facilitates the monitoring of online activities, the exchange of information between teachers and students, adapting different rhythms and learning styles, since it allows offering information in various formats. However the implementation of LMS in the real world has been lower than its offers even with the addition of features such as the grade book, discussion panels, email, elements of social networks such as blogs and wikis, have not supported LMS are enough to keep pace with rapid changes in technology, specifically with types of collaboration and interaction that online social tools have achieved such as Facebook and Twitter ${ }^{43}$. This implies that LMS are not well designed for discussion and collaboration activities ${ }^{44}$, there is no real social interaction. Thus, LMSs have now become simple repositories of files to distribute content $\frac{45}{}$.

The students use LMS tools to a large extent, in more significant numbers the Moodle platform, to support learning activities outside the classroom as a formal communication with teachers, where they find contents that are organized by weeks, modules or topics, with access to resources and activities supervised by a tutor. Breaking the formality can be linked to the educational process SNS, for example with Facebook, which would complement each other to support learning activities outside the classroom, with informal communication with colleagues that allows them to talk in a relaxed manner, answer quick questions, with communication, interaction and social collaboration. Without a doubt, the synergy of these two tools will not be the total solution to the problems of teaching and learning, but it will significantly help the attraction and future adhesion of the student to this new social learning environment. 


\section{Conclusions}

Many of the arguments stated affirm that social networks fulfill the capacity to provide virtual learning communities, with a high degree of student attraction in the social field, with the consequence of factors of integration, collaboration and cooperation. However, by itself it will not cause a relevant impact in the educational field, since the SNS were created for entertainment, informal communication, meeting new people; this requires that without an instructional model that normalizes the educational process, it will not have the expected success. While the LMS, which were born exclusively for training, have methodological and pedagogical aspects of instruction that the SNS suffer. These characteristics that alone have these technological tools can merge into one and be able to adhere their strengths to create an evolutionary educational environment that favors the process of teaching-learning. Works in literature have examined the use of Facebook as an informal learning platform ${ }^{21,23,46}$, but very few studies have examined Facebook as an alternative in the field of education as part of an LMS $\stackrel{47}{ }$. Despite the success and enormous potential in the field of education, so far Facebook is used mainly as an informal learning environment and less for formal educational activities, which leads thinking that this potential directed and merged with the LMS would achieve a significant process in the educational field. However, we should not think that only the synergy of the tools, both formal and informal, will achieve that success; but it is also indisputable to believe that learning develops through instruction where knowledge is developed.

Throughout the investigation it has been demonstrated that the social presence will increase the cognitive learning, and the satisfaction of the students in the education, facilitating the process of adaptation of the participants in a warmer and accessible environment, and assuring the students to express themselves comfortably and without pressure through the virtual learning community based on SNS. This factor is very significant for LMS to get more interaction between educational actors. Therefore, when choosing and designing virtual communities, is essential to consider the functions of interface, communication and knowledge sharing, with a simple and easy-to-use interface, as a feature of adaptability, support and appropriate access speed to give rise to its use. As a consequence, it will contribute to the interferences that SNSs have in synergy with the LMS, which in the context of instruction, will achieve significant learning in students with a strong social influence that will make adherence to this new learning environment.

The social presence, the search for information, and the fulfillment of academic and social activities, mediated by Facebook among the online learning community, will significantly contribute to the students' academic process, since the SNS tools they are easier to use and provide a better interactive area than those integrated in the LMS. Students prefer to use SNS because they are more familiar, more practical when they use smartphones and meet their needs immediately ${ }^{48}$. However, it can be a beneficial tool when the teacher decides to enter consciously into their practices, as it not only allows the passive transmission of information but can also be generated through those didactic activities that enhance face-to-face training. And even more so in some cases that encourage the independent and regulated work of students. The LMS in synergy with the SNS and with compliance with training standards in a formal virtual environment would be technological innovation units for higher education in eLearning and bLearning modalities, causing an interaction, social presence, communication and collaboration between the educational actors. The synergy of these two technological tools will generate a more adaptable education to the individual disciplinary needs, in order to go beyond the closed walls of the LMS, to a learning platform constructed on the basis of socially mediated communities of knowledge, and will help to fulfill the objectives of critical pedagogy to interrupt the formal imbalances of power between the student and the teacher breaking down the walls of formalism.

Students use social networks all the time, sharing information that they would not otherwise share, this constant interaction will be able to take advantage of online learning that will become more participatory than receptive, more based on collaborative content.The use of these tools is not free of problems and challenges, so the role of the teacher is still a determining factor in student performance, and the need to integrate these two tools in academic training, will cause technical and technological infrastructure, with appropriate pedagogical norms that help to develop cognitive skills in a social environment that favors the development of this type of teaching and the student being the protagonist of their own learning.

With the rapid emergence of SNS in the educational environment, it has faced a new way of teaching and learning that without a doubt the lack of new pedagogical models that interact in the informal training process 
has created uncertainty for academic staff, management and students, not being so with the LMS that possess the elements for a formal and instructional teaching-learning process. The synergy of these two technological tools would allow generating a successful platform for the educational process. Everybody knows that universities take a long time to adopt new technologies, this institutional inertia can be a significant obstacle to the adoption of social web technologies and the LMS. Although the LMS offers the educational institution the possibility of preparing for a modern and high- performance education, the synergy with the social tools will help the teachinglearning process and will have the capacity to fulfill the educational requirements of the current university, and at the same time be prepared to face the student, operational and technological needs of the university of the future.

Therefore, it is necessary for universities to face organizational changes that ensure an adequate environment for the full use of new learning systems, which involve both new technologies represented by SNS and LMS, and in general online education, as well as new teaching systems that encourage student participation, as mentioned by Jhonson and colleagues ${ }^{29}$."Any discussion on technology adoption must take into account essential constraints and challenges ... the particular limitations of each organization are the most critical factors that explain the decision to adopt or not a specific technology. Even the institutions that are willing to adopt new technologies are actively restrained by the lack of the necessary human resources and the financial means to carry out these ideas".

\section{Suggestion for Future Researches}

The implementation of models with an educational focus that help the synergy of the LMS and SNS by integrating the approaches; technological, pedagogical, cognitive and social will achieve an environment in which there is a real balance between classroom teaching and virtual potentializing this modality.

\section{References}

1. Ma WWK, Chan A. Knowledge sharing and social media: Altruism, perceived online attachment motivation, and perceived online relationship commitment. Comput Human Behavior. 2014; 39:51-8. https://doi.org/10.1016/j. chb.2014.06.015
2. Hidalgo BG, Hidalgo DP, Hidalgo IM. El impacto de las redes sociales como herramientas de comunicación, interacción y colaboración en el proceso ense-anza aprendizaje en la educación superior. SATHIRI. 2017; 12(1):104-13. Available from: http://revistasdigitales.upec.edu.ec/index. php/sathiri/article/view/56/96

3. Weller M. The centralisation dilemna in educational IT. Internation Journal of Virtual and Personal Learning Environments. 2010; 1(1):1-9. https://doi.org/10.4018/ jvple.2010091701

4. García-Pe-alvo FJ. Revisión sistemática de literatura en los Trabajos de Final de Máster y en las Tesis Doctorales. Grial, Instituto de Ciencias de la Educación, Universidad de Salamanca, Espa-a; 2017.

5. Schryen G. Writing qualitative is literature reviewsGuidelines for synthesis, interpretation, and guidance of research. Communications of the Association for Information Systems. 2015; 37:286-325. https://doi. org/10.17705/1CAIS.03712

6. Li YY, Yang DA, Zhao H. Web of Science ${ }^{\oplus} ; 2006$.

7. UNESCO. Las TIC en la educación. 2018. Available from: https://es.unesco.org/themes/tic-educacion

8. Sánchez RA, Hueros AD. Motivational factors that influence the acceptance of Moodle using TAM. Computers in Human Behavior. 2010; 26(6):1632-40. https://doi. org/10.1016/j.chb.2010.06.011

9. De Smet C, Bourgonjon J, De Wever B, Schellens T, Valcke $M$. Researching instructional use and the technology acceptation of learning management systems by secondary school teachers. Computers and Education. 2012; 58(2):688-96. https://doi.org/10.1016/j.compedu.2011.09.013

10. Gomes A,Guerra H, Mendes A, Rego I. Facebook vs Moodle: Surveying university students on the use of learning management systems to support learning activities outside the classroom. IEEE: 10th Iberian Conference on Information Systems and Technologies (CISTI); 2015. p. 1-4. https://doi.org/10.1109/CISTI.2015.7170464

11. Castro SM, Clarenc CA, De Lenz C, Moreno ME, Tosco N. Analizamos 19 plataformas de e-Learning: Investigación Colaborativa sobre LMS. Ed. Lulu, Argentina; 2013. p. 152. Available from: http://cooperacionib.org/191191138-Analizamos-19-plataformas-de-eLearning-primera-investigacion-academica-colaborativa-mundial.pdf

12. Webometrics. Webmetrics.info; 2017. Available from: http://www.webometrics.info

13. Google Trends; 2018. Available from: https://trends.google. es/trends

14. Pontificia Universidad Javeriana. Proyecto evaluación LMS; 2016. Available from: http://portales.puj.edu.co/ javevirtual/proyecto_evaluacion/documentos/Proyecto_ Evaluacion_LMS.pdf 
15. Ciudad-Gomez A. Teaching innovation and use of the ICT in the teaching-learning process within the new framework of the EHEA, byMeans of Moodle platform. American Journal of Business Education. 2010; 3(13):13-20.

16. Zhang X, Gao Y, Yan X, de Pablos PO, Sun Y, Cao X. From e-learning to social-learning: Mapping development of studies on social media-supported knowledge management. Computersin Human Behavior. 2015; 51(B):803-11.

17. McCarthy J. International design collaboration and mentoring for tertiary students through Facebook. Australasian Journal of Educational Technology. 2012; 28(5):755-75. https://doi.org/10.14742/ajet.1383

18. Bosch TE. Using online social networking for teaching and learning: Facebook use at the University of Cape Town. Communication. 2009; 35(2):185-200.

19. Kenney J, Kumar S, Hart M. More than a social network: Facebook as a catalyst for an online educational community of practice. International Journalof Social Media and Interactive Learning Environments. 2013; 1(4):355-69. https://doi.org/10.1504/IJSMILE.2013.057467

20. Rambe P. Critical discourse analysis of collaborative engagement in Facebook postings. Australasian Journal of Educational Technology. 2012; 28(2):295-314. https://doi.org/10.14742/ajet.875

21. Ritter NL, Delen E. Undergraduates' Facebook use: evidence-based practice to implement social media in education. International Journalof Social Media and Interactive Learning Environments. 2013; 1(4):387-405.https://doi. org/10.1504/IJSMILE.2013.057463

22. Shih R. Can Web 2.0 technology assist college students inlearning English writing? Integrating Facebook and peer assessment with blended learning. Australasian Journal of Educational Technology. 2011; 27(5):829-45. https://doi. org/10.14742/ajet.934

23. Kurtz G. Facebook group as a space for interactive and collaborative learning. International Journal of Social Media and Interactive Learning Environments. 2013; 1(4):406-18. https://doi.org/10.1504/IJSMILE.2013.057461

24. Irwin C, Ball L, Desbrow B, Leveritt M. Students' perceptions of using Facebook as an interactive learning resource at university. Australasian Journal of Educational Technology. 2012; 28(7):1221-32. https://doi.org/10.14742/ajet.798

25. Statistics. Social Networking Statistics. Statistic Brain Research Institute; 2017. Available from: http://www.statisticbrain.com/social-networking-statistics

26. Omar H, Embi MA, Yunus MM. Learners' use of communication strategies in an online discussion via Facebook. Procedia - Social and Behavioral Sciences. 2012; 64:535-44. https://doi.org/10.1016/j.sbspro.2012.11.063

27. Mazman SG, Usluel YK. Modeling educational usage of Facebook. Computers and Education. 2010; 55(2):444-453. https://doi.org/10.1016/j.compedu.2010.02.008
28. Corbí A, Burgos D. LIME: un modelo de recomendación para entornos de aprendizaje online formal/informal. Dialnet. Available from: 2014; 3(1):12-20.

29. Johnson L, Adams S, Estrada V, Freeman A. Horizon Report: 2015 Higher Education Edition; 2015. p. 56. Available from: http://cdn.nmc.org/media/2015-nmc-horizon-report-HEEN.pdf

30. Yilmaz FG. Social presence and transactional distance as an antecedent to knowledge sharing in virtual learning communities. Journal of Educational Computing Research. 2017; 55(6):844-64. https://doi.org/10.1177/0735633116688319

31. YIlmaz R. Knowledge sharing behaviors in e-learning community: Exploring the role of academic self-efficacy and sense of community. Computers in Human Behavior. 2016; 63:373-82. https://doi.org/10.1016/j.chb.2016.05.055

32. Wang X, Laffey J, Xing W, Ma Y, Stichter J. Exploring embodied social presence of youth with Autism in 3D collaborative virtual learning environment: A case study. Computers in Human Behavior. 2016; 55(A):310-21.

33. Wilson RE, Gosling SD, Graham LT. A review of Facebook research in the social sciences. Perspectives on Psychological Science. 2012; 7(3):203-220. https://doi. org/10.1177/1745691612442904 PMid:26168459

34. Pai P, Arnott DC. User adoption of social networking sites: Eliciting uses and gratifications through a meansend approach. Computers in Human Behavior. 2013; 29(3):1039-53. https://doi.org/10.1016/j.chb.2012.06.025

35. Kantola JI, Barath T, Nazir S, Andre T. The usage of social networking sites for education in the higher education context. Advances in Human Factors, Business Management, Training and Education; 2016. p. 225-38.

36. Moretta T, Buodo G. Modeling problematic Facebook use: Highlighting the role of mood regulation and preference for online social interaction. Addictive Behaviors. 2018; 87:214-21.https://doi.org/10.1016/j.addbeh.2018.07.014 PMid:30056306

37. Caplan SE. Theory and measurement of generalized problematic Internet use: A two-step approach. Computers in Human Behavior. 2010; 26(5):1089-97. https://doi. org/10.1016/j.chb.2010.03.012

38. Assunção RS, Matos PM. The generalized problematic internet use scale 2: validation and test of the model to Facebook use. Journal of Adolescence. 2017; 54:51-9. https://doi. org/10.1016/j.adolescence.2016.11.007 PMid:27871015

39. Ryan T, Chester A, Reece J, Xenos S. The uses and abuses of Facebook: A review of Facebook addiction. Journal of Behavioral Addictions. 2014; 3(3):133-48. https://doi.org/10.1556/JBA.3.2014.016 PMid:25317337 PMCid:PMC4189307

40. Xuexiang Y, Kuiyuan Z, Jianjun $H$. The Design and practice of management-teaching-research integration system in continuing education based on social network. IEEE: 
International Conference of Educational Innovation through Technology (EITT); 2015. p. 169-74. https://doi. org/10.1109/EITT.2015.43

41. Gunes A, Altintas T. Evaluation of distance education components: A case study of associate degree programs. Academy of Educational Leadership Journal. 2012; 13(3):23-34.

42. Dahlstrom E, Walker JD, Dziuban C. ECAR study of undergraduate students and information technology; 2014. Available from: http://www.educause.edu/ecar

43. Stern DM, Willits MD. Social media killed the LMS: Re-imagining the traditional learning management system in the age of blogs and online social networks. Wankel C, editor. Educating Educators with Social Media (Cuttingedge Technologies in Higher Education. Emerald Group Publishing Limited; p. 347-73.

44. Zanjani N, Edwards SL, Nykvist S, Geva S. The important elements of LMS design that affect user engagement with e-learning tools within LMSs in the higher education sector. Australasian Journal of Educational Technology. 2017; 33(1):19-31.

45. Rodrigues S, Portugal P, Rocha A, Abreu A. The use of moodle in higher education evolution of teacher's practices over time. IEEE: 12th Iberian Conference on Information Systems and Technologies (CISTI); 2017. p. 1-4. Available from: https://ieeexplore.ieee.org/abstract/ document/7975702/

46. Cheung CMK, Chiu PY, Lee MKO. Online social networks: Why do students use facebook? Computersin Human Behavior. 2011; 27(4):1337-43. https://doi.org/10.1016/j. chb.2010.07.028

47. Wang Q, Woo HL, Quek CL, Yang Y, Liu M. Using the Facebook group as a learning management system: An exploratory study. British Journal of Educational Technology. 2012; 43(3):428-38. https://doi.org/10.1111/ j.1467-8535.2011.01195.x

48. Garavaglia A, Petti L. University student communities and media habits: From Formal LMS to Social Networks. Procedia- Social and Behavioral Sciences. 2015; 197:898903. https://doi.org/10.1016/j.sbspro.2015.07.270

49. Linne J. La «multimidad»: performances íntimas en Facebook de adolcescentes de Buenos Aires. Estudios Sociológicos de el colegio de México. 2016; 34(100):65-84. Available from: https://estudiossociologicos.colmex.mx/ index.php/es/article/view/1389 